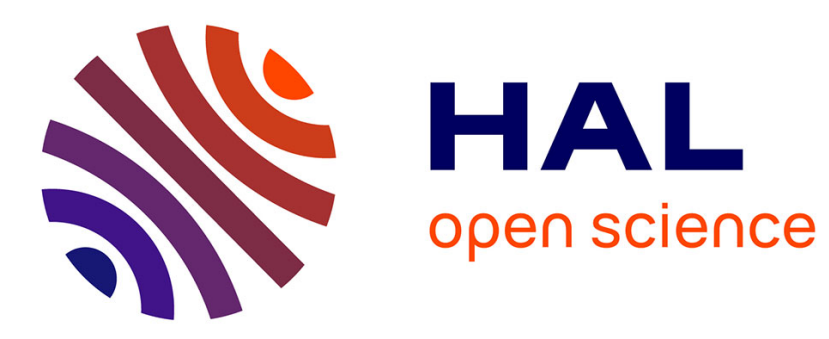

\title{
Dynamic rupture simulations on a fault network in the Corinth Rift
}

\author{
Virginie Durand, Sébastien Hok, Aurélien Boiselet, Pascal Bernard, Oona
}

Scotti

\section{- To cite this version:}

Virginie Durand, Sébastien Hok, Aurélien Boiselet, Pascal Bernard, Oona Scotti. Dynamic rupture simulations on a fault network in the Corinth Rift. Geophysical Journal International, 2017, 208, pp.1611 - 1622. 10.1093/gji/ggw466 . hal-01456326

\section{HAL Id: hal-01456326 \\ https://hal.science/hal-01456326}

Submitted on 14 Feb 2017

HAL is a multi-disciplinary open access archive for the deposit and dissemination of scientific research documents, whether they are published or not. The documents may come from teaching and research institutions in France or abroad, or from public or private research centers.
L'archive ouverte pluridisciplinaire HAL, est destinée au dépôt et à la diffusion de documents scientifiques de niveau recherche, publiés ou non, émanant des établissements d'enseignement et de recherche français ou étrangers, des laboratoires publics ou privés. 


\title{
Dynamic rupture simulations on a fault network in the Corinth Rift
}

\author{
V. Durand, ${ }^{1}$ S. Hok, ${ }^{2}$ A. Boiselet ${ }^{3}$ P. Bernard ${ }^{1}$ and O. Scotti ${ }^{2}$ \\ ${ }^{1}$ Institut de Physique du Globe de Paris, Sismologie, Paris, France, E-mail: vdurand@ipgp.fr \\ ${ }^{2}$ IRSN, Bureau des Risques Sismiques pour la Sûreté des Installations, Paris, France \\ ${ }^{3}$ AXA Global P\&C, Paris, France
}

Accepted 2016 December 9. Received 2016 December 5; in original form 2016 March 10

\begin{abstract}
SUMMAR Y
The Corinth rift (Greece) is made of a complex network of fault segments, typically 10-20 km long separated by stepovers. Assessing the maximum magnitude possible in this region requires accounting for multisegment rupture. Here we apply numerical models of dynamic rupture to quantify the probability of a multisegment rupture in the rift, based on the knowledge of the fault geometry and on the magnitude of the historical and palaeoearthquakes. We restrict our application to dynamic rupture on the most recent and active fault network of the western rift, located on the southern coast. We first define several models, varying the main physical parameters that control the rupture propagation. We keep the regional stress field and stress drop constant, and we test several fault geometries, several positions of the faults in their seismic cycle, several values of the critical distance (and so several fracture energies) and two different hypocentres (thus testing two directivity hypothesis). We obtain different scenarios in terms of the number of ruptured segments and the final magnitude (between $M=5.8$ for a single segment rupture to $M=6.4$ for a whole network rupture), and find that the main parameter controlling the variability of the scenarios is the fracture energy. We then use a probabilistic approach to quantify the probability of each generated scenario. To do that, we implement a logical tree associating a weight to each model input hypothesis. Combining these weights, we compute the probability of occurrence of each scenario, and show that the multisegment scenarios are very likely ( 52 per cent), but that the whole network rupture scenario is unlikely (14 per cent).
\end{abstract}

Key words: Numerical approximations and analysis; Earthquake dynamics; Dynamics and mechanics of faulting.

\section{INTRODUCTION}

The Corinth rift, located in central Greece (Fig. 1), is one of the most seismically active areas in Europe. Its western part is the fastest extensional region in Europe, with geodetic opening rates of 14 to $16 \mathrm{~mm} \mathrm{yr}^{-1}$ (Briole et al. 2000; Avallone et al. 2004), and it produces several earthquakes above magnitude 5.5 per century (Ambraseys \& Jackson 1997; Hatzfeld et al. 2000; LyonCaen et al. 2004), together with a large and highly fluctuating microseismic background in the form of seismic swarms (Rigo et al. 1996; Bernard et al. 2006; Pacchiani \& Lyon-Caen 2010; Lambotte et al. 2014). The most active normal faults, dipping to the north and striking NWN-ESE, crop out near the southern coast (Stefatos et al. 2002; Avallone et al. 2004), and root around 6-8 km in depth (Lambotte et al. 2014), with the exception of the blind, north dipping offshore fault activated during the 1995, $M=6.2$ event (Bernard et al. 2006). They are mainly en echelon faults, with small segments (between 10 and $20 \mathrm{~km}$ long) close from each other. In this study, we consider a fault system located on the southern coast of Corinth Gulf, composed of the Psathopyrgos (Ps), Neos-Erineos
(N) and Aigion (A) faults (Fig. 1). At least three historical earthquakes of magnitude greater than 6 can be associated to the Aigion fault: in 1748, 1817 and 1888 (Papazachos \& Papazachou 1997; Pantosti et al. 2004). The last one may have jointly ruptured the Aigion fault and the eastern Neos Erineos system. On another hand, at least one is assumed to have occurred on the Psathopyrgos fault, in 1756 (Papazachos \& Papazachou 1997). The paleoearthquakes attributed to these faults show large surface displacements $(0.4$ $0.7 \mathrm{~m}$ ), corresponding to magnitudes of the order of 6.5 (Pantosti et al. 2004). However, the typical length of the surface traces of faults in the southwestern part of the Gulf is about $10 \mathrm{~km}$. This length is too small to produce such high magnitudes, which suggests that the successive rupture of several fault segments in a single dynamic event is likely to occur; the magnitudes estimated for multisegment ruptures are larger than the ones obtained with separate ruptures (Boiselet 2014).

Rupture can propagate on several faults if the inter-fault distance is smaller than $5 \mathrm{~km}$ (Wesnousky 2008; Boiselet 2014). However, on the southern coast of the Corinth Gulf, the criteria of a distance of $5 \mathrm{~km}$ allows to connect all the faults of the rift (Fig. 1). 

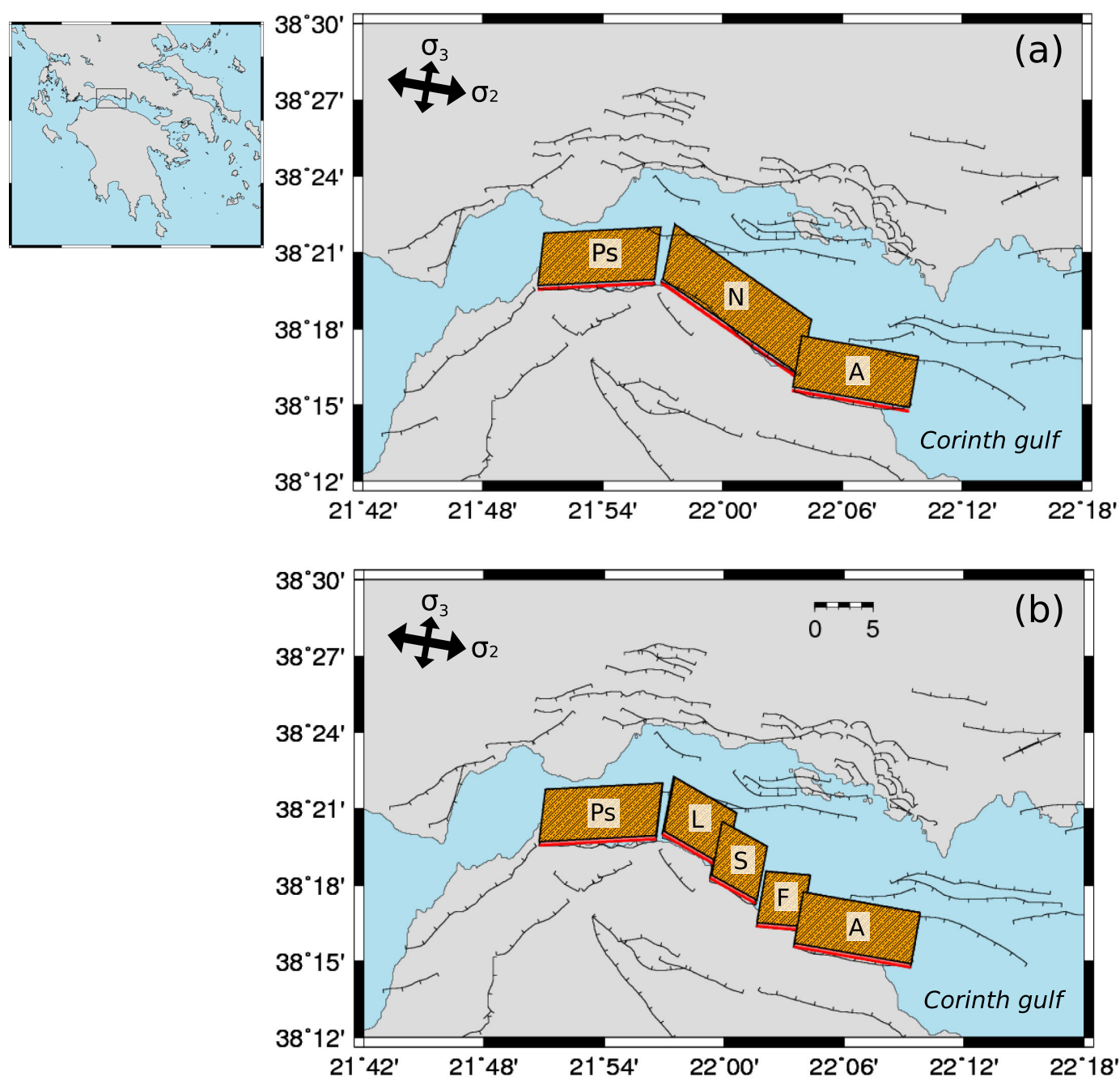

Figure 1. Maps of the different fault geometries used in this study. The inset shows the location of the studied area (rectangle). The fault traces (black lines) are from N. Meyer (personal communication, 2014). The orange parallelograms are the projections on the map of the fault models used. The red lines show the surface traces of the modelled faults if they reached the surface. The black arrows show the directions of the maximum $\left(\sigma_{2}\right)$ and minimum horizontal regional stresses $\left(\sigma_{3}\right)$. (a) Three-fault model. From west to east-Ps: Psathopyrgos fault; N, Neos-Erineos fault; A: Aigion fault. (b) Five-fault model. From west to east—Ps: Psathopyrgos fault, L, Lambiri fault, S, Selianitika fault, F, Fassouleika fault, A, Aigion fault.

Consequently, to evaluate the multisegment rupture possibility in the southern shore of the western Corinth Gulf, Boiselet (2014) considers inter-fault distances smaller than $1.5 \mathrm{~km}$ and shows that, moving westward, the Aigion fault, the Neos-Erineos fault system and the Psathopyrgos fault (Fig. 1), which have similar orientation and dip, can be connected. These faults, separated by less than $1.5 \mathrm{~km}$, have lengths around $10 \mathrm{~km}$ (Table 1). Following the scaling laws of Wells \& Coppersmith (1994) and Leonard (2010), this multisegment scenario can produce earthquakes with magnitudes between 6.1 and 7.0.

In the present study, we select the fault system above, connecting the Aigion to the Psathopyrgos faults, as it is the most active one in the western rift. Our aim is to assess the probability of a scenario in which several of these fault segments break in cascade, and to evaluate the maximum reachable magnitude on this network from the various plausible scenarios, in order to better assess the local seismic hazard. Indeed the seismic hazard evaluation strongly depends on the maximum magnitude of earthquakes expected in a given region, such as in the western Corinth Rift (Boiselet 2014). Apart from improving the local knowledge, our study also aims at highlighting possible benefits from physics-based simulations to reduce uncertainties on maximum magnitude evaluation. Rupture cascading can be studied through dynamic simulations. Earthquake dynamics can help to understand if jumping is physically possible on a fault network, and many authors attend to this problem (Harris et al. 1991; Kase \& Kuge 1998; Andrews \& Schwerer 2000; Aochi \& Fukuyama 2002; Oglesby 2005; Aochi et al. 2006; Finzi \& Langer 2012; Urata et al. 2012; Aochi \& Ulrich 2015; Douilly et al. 2015; Lozos et al. 2015). However, most of the publications deal with strike-slip fault networks.

Apart from the importance of giving information to assess the seismic hazard in the region, the study of rupture propagation in the Corinth Gulf is interesting for modelling dynamic rupture. Indeed, its seismicity and geology are intensively studied (among others, the SISCOR project), making integration of various observations possible. Furthermore, the geometrical configuration of the Aigion to Psathopyrgos fault network is a quite simple case-study for modelling multisegment rupture.

To evaluate the conditions for a multisegment rupture and estimate the associated magnitudes from our a priori knowledge of the 
fault geometry, stress field and past earthquakes, we use a physically based earthquake modelling, and run several numerical simulations of dynamic rupture propagation along this fault network. Given the uncertainties on the model parameters, we test several parameter combinations to evidence which kinds of rupture scenario are possible. We focus on the interactions between the fault segments. As done by Aochi et al. (2006) for the Middle Durance (France) fault system, we use a logic-tree approach to consider the parameters variability in the statistical study we perform. From this perspective, each parameter is weighted, in order to quantify each scenario representativeness. In our study the final probability is different from the probability of occurrence used in probabilistic seismic hazard analysis (PSHA). Here we assume that the critical state of stress to trigger an earthquake is reached, and compute the probability of getting an earthquake of a given magnitude knowing this. Therefore we do not take the magnitude-frequency relationship into account.

\section{NUMERICAL METHOD}

We compute the spontaneous rupture propagation along the faults with a dynamic approach, by using the numerical code developed by Hok \& Fukuyama (2011). The code is based on the boundary integral equation method (BIEM, Aochi et al. 2000; Tada et al. 2000), and is able to model 3-D non-planar and non-continuous faults, embedded in a homogeneous elastic medium. The BIEM method has been applied to study large earthquake ruptures (Aochi \& Fukuyama 2002; Hok \& Fukuyama 2011; Hok et al. 2011), and dynamic propagation of rupture on several faults (Aochi et al. 2006; Aochi \& Ulrich 2015; Douilly et al. 2015).

Hok \& Fukuyama (2011) improved the code so that it includes a free surface, which is needed in the case of the rupture of dipping faults, such as here for the Corinth rift normal faults. The effect of free surface is to reflect the body waves radiated by the rupture back on to the fault plane, which will interact with it and contribute to the rupture process, altogether with the induced surface waves.

The different parameters used in the model are the fault geometry, the stress field, the hypocentre location, the frictional coefficients, and the position of each fault in its seismic cycle.

\section{NUMERICAL SIMULATIONS}

For this study, we carry out spontaneous dynamic rupture simulations for 64 parameter sets (Fig. 2). Besides testing the influence of each parameter on the rupture propagation, we also estimate their probabilities. Indeed, considering a multisegment fault network, we could generate different rupture scenarios. The magnitudes we obtain are ranging from 5.8 to 6.4. For seismic hazard assessment, these different earthquake scenarios, depending on the parameters of the model, need to be associated to a probability of occurrence.

To obtain the probability of occurrence of a given scenario, we allocate different weights to each parameter. We then multiply these weights:

$$
P(\text { scenario })=P_{1} * P_{2} * P_{3} * P_{4} * P_{5} \text {. }
$$

It gives us the probability of the different scenarios we generate. The $P_{1}$ to $P_{5}$ probabilities are defined in the following paragraphs.

Some parameters are constant for all the simulations. This is the case for the global parameters such as the $S$-wave $\left[V_{\mathrm{S}}=3000 \mathrm{~ms}^{-1}\right.$, in agreement with the velocity models from Rigo et al. (1996) and Drakatos et al. (1997)] and $P$-wave $\left(V_{\mathrm{P}}=5196 \mathrm{~ms}^{-1}\right)$ velocities, and the density $\rho=2700 \mathrm{~kg} \mathrm{~m}^{-3}$. The time-step is $0.02 \mathrm{~s}$, the nucleation zone radius is $2 \mathrm{~km}$, and the initial overshoot used to force nucleation is $0.1 \mathrm{MPa}$.

\subsection{Fault models $\left(P_{1}\right)$}

The GPS observations indicate that the stress field in the study region is extensional. The extension direction, of N10E, gives us the direction of the principal stress component $\sigma_{3}$. We use the 2001 earthquake, which had a mixed normal/strike-slip mechanism (Pacchiani \& Lyon-Caen 2010), to constrain the relative values of the principal horizontal stresses. This earthquake is not located on the fault system we study here, but on a fault $20 \mathrm{~km}$ south. However, it gives us valuable information on the regional stress field (Pacchiani \& Lyon-Caen 2010). We obtain the following relation between the stresses:

$\sigma_{1}=\sigma_{2}>\sigma_{3}$

with $\sigma_{1}=\rho g z$ being the vertical stress, considering $g=9.81 \mathrm{~m} \mathrm{~s}^{-1}$, $z$ the depth, and $\sigma_{3}=\frac{1}{3} \sigma_{1}$. As a consequence, the stress field we use is depth-dependent. Moreover, we keep it uniform over the study region, resulting in different stress levels on differently oriented fault segments.

We study two models with different geometries: (1), a simple geometry with three segments (Fig. 1a), and (2), a complex geometry with five segments (Fig. 1b). In both cases, there is no connection between the segments: the dip extension of the fault edges are supposed to be subparallel. This is to avoid depth dependence in the distance between the fault planes, as it is the case if the fault segments are rectangles. In our model, this is simply achieved by assuming that faults are parallelograms. To construct them, we deform the initial rectangular faults so that the projections at the surface of their dipping edges are parallel to the extension direction $(\mathrm{N} 10 \mathrm{E})$. In all the models, each fault is planar, and dips 60 degrees to the north, starting at the surface. We discretize the faults into isosceles triangles with $500 \mathrm{~m}$ long edges. Two triangles form one square element (Table 1). The fault slip (scarp) at the free surface is not modelled here: seismic slip on the fault is restricted from $500 \mathrm{~m}$ below the free surface to $7 \mathrm{~km}$ in depth. Allowing dynamic rupture of the shallowest part of the fault would require a more careful modelling of the propagation of the rupture at the free surface, as well as a better knowledge of the mechanical properties of the very shallow crust, but this level of refinement was not needed for the simple scope of the present paper aiming at the first order cross-triggering properties of neighbouring segments.

Strikes and lengths (Table 1) for the five-fault model are determined from the surface traces reported by Meyer and Ford (personal communication, 2014). The five faults are, from west to east: Psathopyrgos (Ps), Lambiri (L), Selianitika (S), Fassouleika (F) and Aigion (A). For the three-fault model, we use the strike and length reported by Boiselet (2014). What allows us to consider the three central segments (F, S and L) as a unique fault, called Neos-Erineos (N) (Pantosti et al. 2004; Palyvos et al. 2005), is that they are spaced by less than $1 \mathrm{~km}$ (Palyvos et al. 2005; Boiselet 2014).

According to the opinion of geologists from the SISCOR project (M. Ford, personal communication, 2014), the probability that the fault network is composed of only three segments is small compared to the one for five segments. Accordingly, we define the fault geometry weight as follows

$\left\{\begin{array}{l}P_{1}(\text { simple })=0.10 \\ P_{1}(\text { complex })=0.90\end{array}\right.$ 
(4)

Critical slip

displacement

(3)

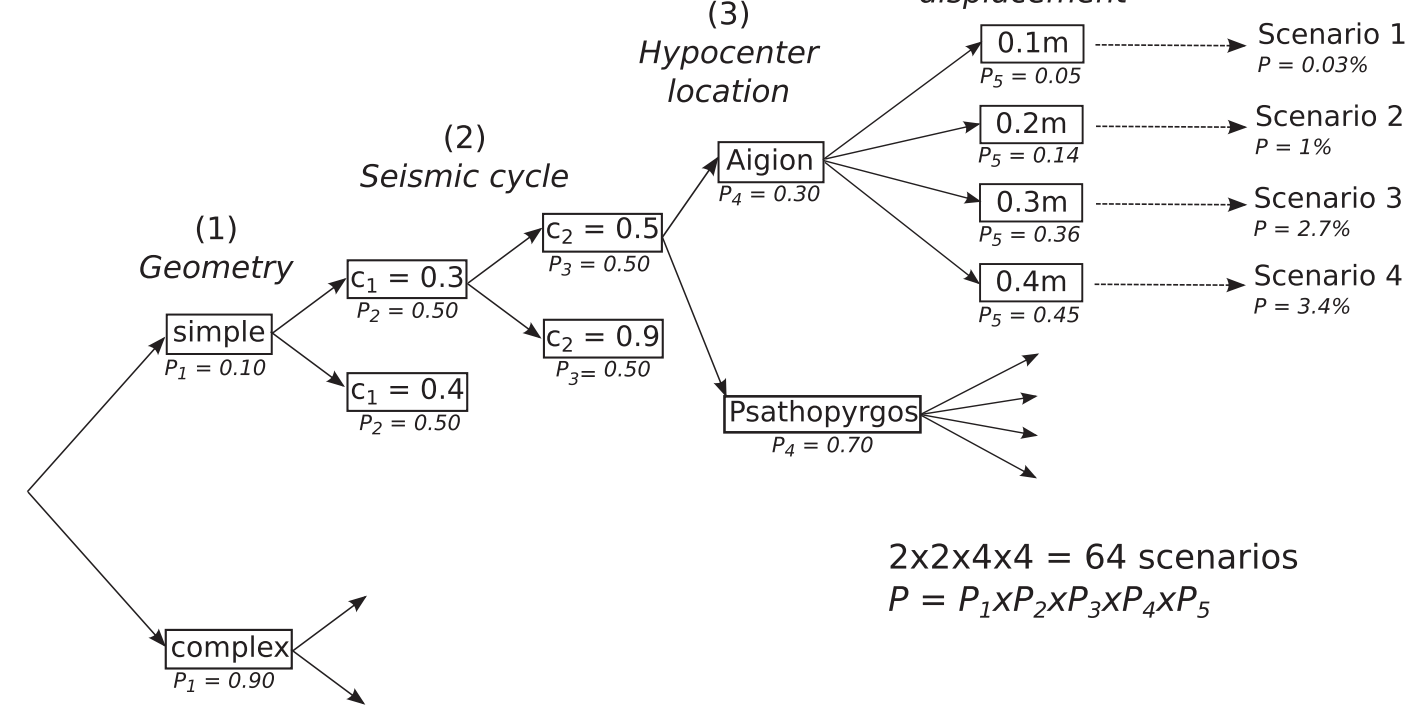

Figure 2. Logic tree describing the different parameters and values explored in the different rupture scenarios. All the parameters and weighting choices are explained in the text.

Table 1. Fault parameters for the two tested geometries.

\begin{tabular}{|c|c|c|c|c|c|c|c|}
\hline \multirow[t]{2}{*}{ Fault name } & \multirow[t]{2}{*}{$\begin{array}{l}\text { Length } \\
\text { (m) }\end{array}$} & \multirow[t]{2}{*}{$\begin{array}{l}\text { Dip } \\
\text { (deg.) }\end{array}$} & \multirow[t]{2}{*}{$\begin{array}{l}\text { Strike (deg.) } \\
\text { (from North) }\end{array}$} & \multirow[t]{2}{*}{$\begin{array}{l}\text { Depth } \\
\text { (m) }\end{array}$} & \multicolumn{2}{|c|}{$\begin{array}{l}\text { Number of } \\
\text { elements }\end{array}$} & \multirow{2}{*}{$\begin{array}{l}\text { Angle of the } \\
\text { parallelogram } \\
\text { (deg.) }\end{array}$} \\
\hline & & & & & $\begin{array}{l}\text { Along } \\
\text { strike }\end{array}$ & $\begin{array}{l}\text { Along } \\
\text { dip }\end{array}$ & \\
\hline \multicolumn{8}{|c|}{ Geometry: 3-fault segments } \\
\hline Psathopyrgos (Ps) & 8505 & 60 & 87 & 7000 & 16 & 15 & 10 \\
\hline Neos Erineos (N) & 12143 & 60 & 125 & 7000 & 24 & 15 & -25 \\
\hline Aigion (A) & 8621 & 60 & 100 & 7000 & 16 & 15 & 0 \\
\hline \multicolumn{8}{|c|}{ Geometry: 5-fault segments } \\
\hline Psathopyrgos (Ps) & 8505 & 60 & 87 & 7000 & 16 & 15 & 10 \\
\hline Lambiri (L) & 5186 & 60 & 120 & 7000 & 10 & 15 & -20 \\
\hline Selianitika (S) & 3759 & 60 & 119 & 7000 & 7 & 15 & -19 \\
\hline Fassouleika (F) & 3225 & 60 & 95 & 7000 & 6 & 15 & 5 \\
\hline Aigion (A) & 8621 & 60 & 100 & 7000 & 16 & 15 & 0 \\
\hline
\end{tabular}

\subsection{Seismic cycle $\left(\boldsymbol{P}_{2}\right.$ and $\left.\boldsymbol{P}_{3}\right)$}

A simple physical assumption is that the stress loading will increase on the fault as the seismic cycle advances. The most simple hypothesis for the loading is a linear increase of stress as a function of time, as long as the deformation rate remains constant. We use a proxy for this seismic cycle advance; we represent the position of each fault in the seismic cycle by the parameter $c$, equal to 0 just after an earthquake occurred (beginning of the cycle), and to 1 at the end of the seismic cycle. The other assumption we make is to consider that the return period (the duration of a cycle) is known. We test two values of $\mathrm{c}$ for each fault segment, based on the historical seismicity and return time estimated for each fault (Boiselet 2014).

\subsubsection{Aigion, Neos-Erineos or Lambiri, Selianitika and Fassouleika faults $\left(c_{1}\right)$}

The Aigion segment rupture has an estimated return time of $390 \mathrm{yr}$, with an incertitude of $\pm 195 \mathrm{yr}$ (table 4.9 of Boiselet 2014). The last earthquake on this fault occurred in 1888 , that is, $128 \mathrm{yr}$ ago.
According to these values, the fault is presently at about 35 per cent of its cycle. So we choose two c values that bracket this estimated cycle position: $c=0.3$ and $c=0.4$. Because these values are chosen arbitrarily, we assume an equal probability for each of them:

$$
\left\{\begin{array}{l}
P 2\left(c_{1}=0.3\right)=0.5 \\
P 2\left(c_{1}=0.4\right)=0.5
\end{array}\right.
$$

We consider the same $c$ values for the three faults that constitute the Neos-Erineos fault system (Boiselet 2014). We proceed the same way as for the Aigion segment. The rupture of the NeosErineos fault system has an estimated return time of $370 \mathrm{yr}$, with an incertitude of $\pm 185 \mathrm{yr}$ (table 4.9 of Boiselet 2014). Given the high magnitude of the 1888 earthquake (M6.3), it is inferred that the Neos-Erineos segment ruptured at the same time as the Aigion segment. Consequently, we consider that it is at the same position in its cycle as the Aigion segment.

Thus, the $c_{1}$ parameter represents the advancement of each fault in its seismic cycle. 

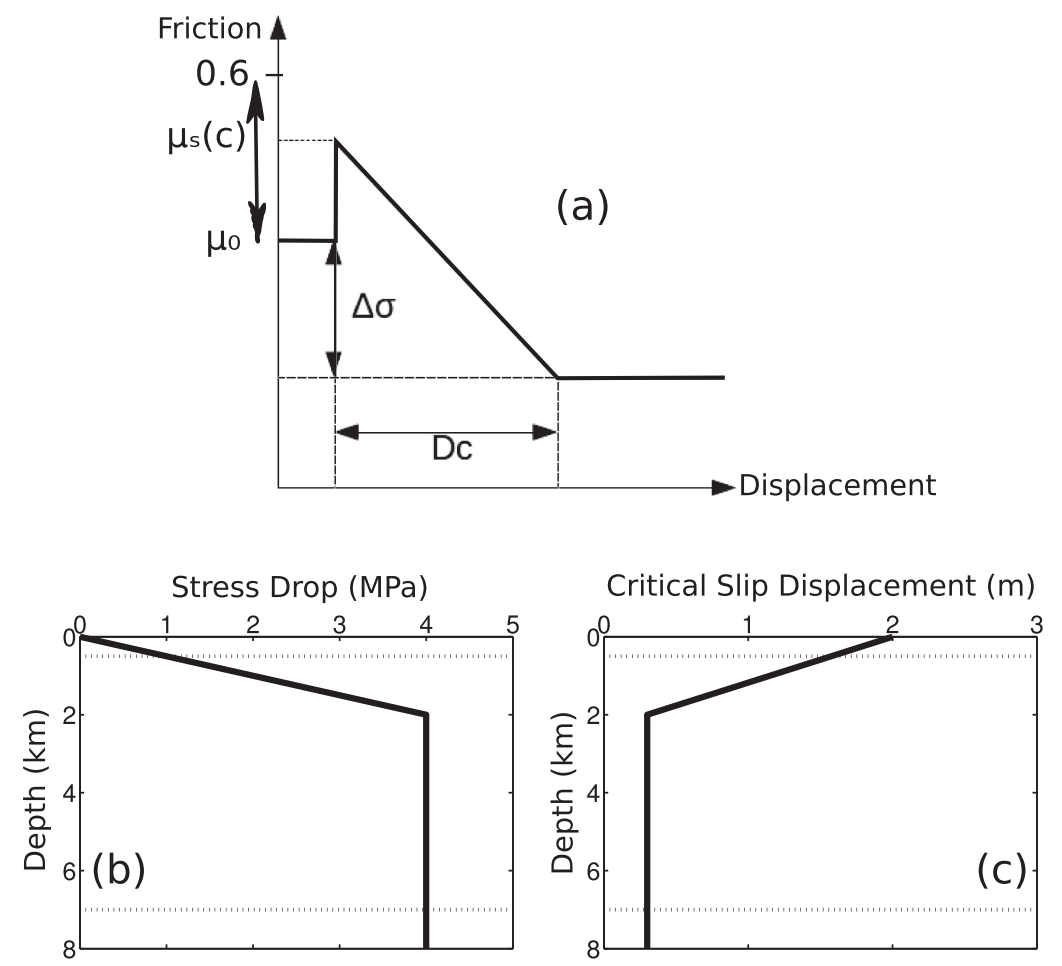

Figure 3. Illustration of the parameters used in the friction law. (a) Slip-weakening law. $D_{c}$ is the critical slip displacement, $\mu_{S}$ is the static friction coefficient which varies from $\mu_{0}$ up to 0.6 , depending on the fault's seismic cycle. $\Delta \sigma$ is the stress drop. (b) Dependence of the stress drop on the depth. The dotted lines show the upper and lower limits of the faults. (c) Dependence of the critical slip displacement on the depth. The dotted lines show the upper and lower limits of the faults.

\subsubsection{Psathopyrgos fault ( $\left.c_{2}\right)$}

The Psathopyrgos segment rupture has an estimated return time of $350 \mathrm{yr}$, with an incertitude of $\pm 175 \mathrm{yr}$ (table 4.9 of Boiselet 2014). The last earthquake on this fault occurred most probably in 1756 , that is, $260 \mathrm{yr}$ ago. According to these values, the fault is now around 75 per cent of its cycle. In the same way as previously, we choose two $\mathrm{c}$ values that bracket this roughly estimated cycle position, $c=0.5$ and $c=0.9$ and we assume an equal probability:

$$
\left\{\begin{array}{l}
P 3\left(c_{2}=0.5\right)=0.5 \\
P 3\left(c_{2}=0.9\right)=0.5
\end{array}\right.
$$

\subsection{Hypocentre location $\left(P_{4}\right)$}

We test two hypocentre locations for each geometry: on the Aigion and Psathopyrgos faults. The choice of these faults is based on the a priori that they are the most likely to generate rupture. This is mostly constrained by historical seismicity and by the fact that they are the main faults of the system. On the Aigion fault, the hypocentre is located at the eastern extremity and bottom of the segment $(x=25 \mathrm{~km} ; y=-6 \mathrm{~km} ; z=-5.5 \mathrm{~km})$. On the Psathopyrgos fault, it is at the western extremity and bottom of the fault $(x=2.5 \mathrm{~km}$; $y=3 \mathrm{~km} ; z=-5.5 \mathrm{~km}$ ). According to expert opinion (SISCOR team, personal communication, 2014), based on relative advance in the seismic cycle of these faults,

$$
\left\{\begin{array}{l}
P 4(\text { Aigion })=0.3 \\
P 4(\text { Psathopyrgos })=0.7
\end{array}\right.
$$

\subsection{Rupture criterion $\left(P_{5}\right)$}

We assume a slip-weakening friction law on the faults (Fig. 3a, Ida 1972; Andrews 1976). The friction decreases with ongoing slip $\Delta u$, until a characteristic length, $D_{c}$, is reached (Fig. 3a):

$\sigma(\Delta u)=\mu_{f}+\left(\mu_{s}-\mu_{f}\right)\left(1-\frac{\Delta u}{D_{c}}\right) H\left(1-\frac{\Delta u}{D_{c}}\right)$,

where $H($.$) is a Heaviside function, \mu_{S}$ and $\mu_{f}$ are the static friction and the final friction coefficients, respectively. $D_{c}$ is called the critical slip distance. Its value for earthquakes is debated. Ide \& Takeo (1997) showed that this distance is equal to several tens of centimetres for the $M_{\mathrm{w}} 6.9$ Kobe earthquake.

In our simulations, we consider $D_{c}$ and the stress drop $\Delta \sigma$ constant in the seismogenic zone where the rupture nucleates, at more than $2 \mathrm{~km}$ in depth. The shallow layers of the crust are usually unfavourable to rupture propagation (Scholz 1988). This is mainly due to the presence of unconsolidated material in the fault (thick gouge or young sediments), with a velocity strengthening behaviour (Marone \& Scholz 1988). Particularly for the Corinth rift faults, the consolidated pre-extension basement is believed to be around $2 \mathrm{~km}$ depth on the hanging wall side (Westaway 2002). Furthermore, according to Ide \& Takeo (1997), $D_{c}$ is larger near the surface than at depth. In order to mimic the strengthening behaviour of the uppermost crust, we damped rupture propagation by linearly increasing $D_{c}$ from $2 \mathrm{~km}$ depth up to the free surface. Below $2 \mathrm{~km}$ in depth, $\Delta \sigma$ is equal to $4 \mathrm{MPa}$. We chose this value by trial and error; it is consistent with the magnitudes around 6 observed on the considered faults (Boiselet 2014). The initial and final stresses are different on each segment, due to the difference in fault orientation. However, we force them to result in a constant stress drop from one fault to the 
other. Furthermore, because we assume depth-dependent lithostatic stresses and $\mu_{S}$ uniform, $\mu_{f}$ has to be increasing linearly with depth, in order to have a constant stress drop.

In the nature, a fault will break as its stress loading reaches its frictional resistance. This is what happen at the end of a seismic cycle, after the stress increased for years on the fault. The dynamic release of accumulated stress starts from this point during the rupture process that we model here in our scenarios. Given our hypothesis that the stress drop is constant (i.e. does not depend on seismic cycle for instance), the only effect of seismic cycle which remains is that the stress and the strength are getting closer as the time passes. The initial friction, $\mu_{0}$, equal to the ratio of initial shear and normal stresses, depends on the fault orientation, but is uniform on each fault. We chose the static coefficient of friction, $\mu_{S}$ (Fig. 3a), based on the fault's position within its seismic cycle:

$\mu_{S}(c)=(1-c) \mu_{S \max }+c \mu_{0}$,

with

$$
\left\{\begin{array}{l}
c=\frac{T_{\text {sincelast } E Q}}{T_{\text {return }}} \\
\mu_{S}(c=0)=\mu_{S \max }=0.6 \text { at the beginning of the seismic cycle } \\
\mu_{S}(c=1)=\mu_{0} \text { at the end of the seismic cycle. }
\end{array}\right.
$$

This choice is a simple approximation to take the seismic cycle into account without having to introduce a complex modelling of the shear stress loading. The simplification (reduction of shear strength instead of an increase of loading) is a convenient way to account for the heterogeneity and variability of the position in seismic cycle along the modelled fault network. Here we don't model the full seismic cycle loading stress distribution (through deformation history around the fault, or creeping at the bottom for instance), nor rigorous initiation mechanism (increase of pore pressure, increase of slip velocity, etc.). Our assumption will produce more fracture energy for segments that are supposed to be far from breaking in their seismic cycle.

The value of the $D_{c}$ parameter is not well constrained by observations (see discussions in Cocco et al. 2009; Cruz-Atienza et al. 2009), due to our limited knowledge of short-length scale rupture characteristics (Guatteri \& Spudich 2000). As a consequence, $D_{c}$, evaluated from shear traction evolution retrieved from kinematic source models, scales with final slip. For instance, Mikumo et al. (2003) obtained values of $D_{c}$ ranging from 27 per cent to 56 per cent of final slip. Tinti et al. (2005) and Hok \& Fukuyama (2011) found that $D_{c}$ could be a large fraction of the final slip up to 100 per cent of the final slip. Consequently, in dynamic modelling, values are often defined in an ad hoc manner. For example, Pulido \& Dalguer (2009) chose $D_{c}$ to be 20 per cent of the final slip, varying over the fault plane. Aochi et al. (2006) used an uniform $50 \mathrm{~cm}$ value to simulate earthquake dynamics for different scenarios with magnitudes ranging from 6.3 to 6.9, while Aochi \& Ulrich (2015) chose $80 \mathrm{~cm}$ for earthquakes with magnitudes ranging from 5.5 to $7.5 . D_{c}$ appears to be scale dependent (Cocco et al. 2009), and controlled by fault roughness, gouge width, heterogeneities of fault properties, and experimental sample size.

In the present study, we explore four different values of $D_{c}$ at depth, as specified on Fig. 2. They range between 0.1 and $0.4 \mathrm{~m}$, which seems reasonable for our target earthquake size of magnitude 6 , for which the maximum expected slip should be around $1 \mathrm{~m}$. Our minimal value, $D_{c}=0.1 \mathrm{~m}$, is chosen on the basis of our fault element resolution, which does not allow shorter $D_{c}$. The maximal value, $D_{c}=0.4 \mathrm{~m}$, corresponds to the longer critical length allowing the rupture to extend out from our nucleation zone. $D_{c}$ depth distribution is the same for all the faults within a scenario.

There was no clear evidence to balance the different hypotheses considered beforehand. However, the fracture energy of earthquakes, which depends on $D_{c}$, is probably better constrained by data than $D_{c}$ (Guatteri \& Spudich 2000; Cocco et al. 2009). Many studies established scaling relationships between earthquake fracture energy $G_{c}$ and moment $M_{0}$ (see Causse et al. 2014 and references therein). Causse et al. (2014) found the following scaling law between $G_{c}$ and $M_{0}$ :

$\log 10\left(G_{c}\right)=0.60 * \log 10\left(M_{0}\right)-11.6$,

with a dispersion of 0.43 between the moment and the fracture energy, based on kinematic source database analysis. Using this law, we computed the fracture energy for all our rupture scenarios. Then we plotted our results against this scaling law (Fig. 4). Each of them was assigned a mark relative to their position compared to the median and standard deviation of the scaling law. By gathering the scenarios by value of $D_{c}$ (Fig. 4), we established a weight for each hypothesis:

$\left\{\begin{array}{l}P_{5}\left(D_{c}=0.1\right)=0.05 \\ P_{5}\left(D_{c}=0.2\right)=0.14 \\ P_{5}\left(D_{c}=0.3\right)=0.36 \\ P_{5}\left(D_{c}=0.4\right)=0.45\end{array}\right.$

These weights are thus based on the likeliness that the ratio of the fracture energy (through $D_{c}$ ) to the final seismic moment of the scenario is compatible with the Causse et al. (2014) scaling law. The weight of the $D_{c}=0.4$ hypothesis is thus ten times the weight of the $D_{c}=0.1$ one. This reflects the fact that for the range of magnitude we obtained, the former is more likely to be representative of the scaling observed in the data for the fracture energy growth with earthquake size.

\section{RESULTS}

To verify that our choice of parameters is in agreement with earthquake data, we compare our results with the scaling law defined by Leonard (2010). He provides several scaling laws between earthquake source parameters such as magnitude, slip, length and area from available data sets. This type of scaling laws are commonly used in seismic hazard studies to link geological information to potential seismic sources. We find that our sets of parameters give results consistent with the scaling law between average slip and rupture area (Fig. 5).

\subsection{Sensitivity Tests}

\subsubsection{The three-fault geometry}

The simulations with the simplest geometry give results that follow a bimodal behaviour (Fig. 6 and Table 2): either the rupture propagates only on the nucleation fault, or it propagates across all three faults. We clearly see the influence of the $D_{c}$ parameter: the rupture stays on the nucleation fault for $D_{c}$ greater than $0.2 \mathrm{~m}$, and propagates across all three faults for $D_{c}$ smaller or equal to $0.2 \mathrm{~m}$. But we do not observe any influence of the position of the faults in the seismic cycle nor of the hypocentre location: the scenarios are the same, whether the rupture nucleates on the Aigion or on the Psathopyrgos fault. We propose that this bimodal behaviour is due to the orientation of the 


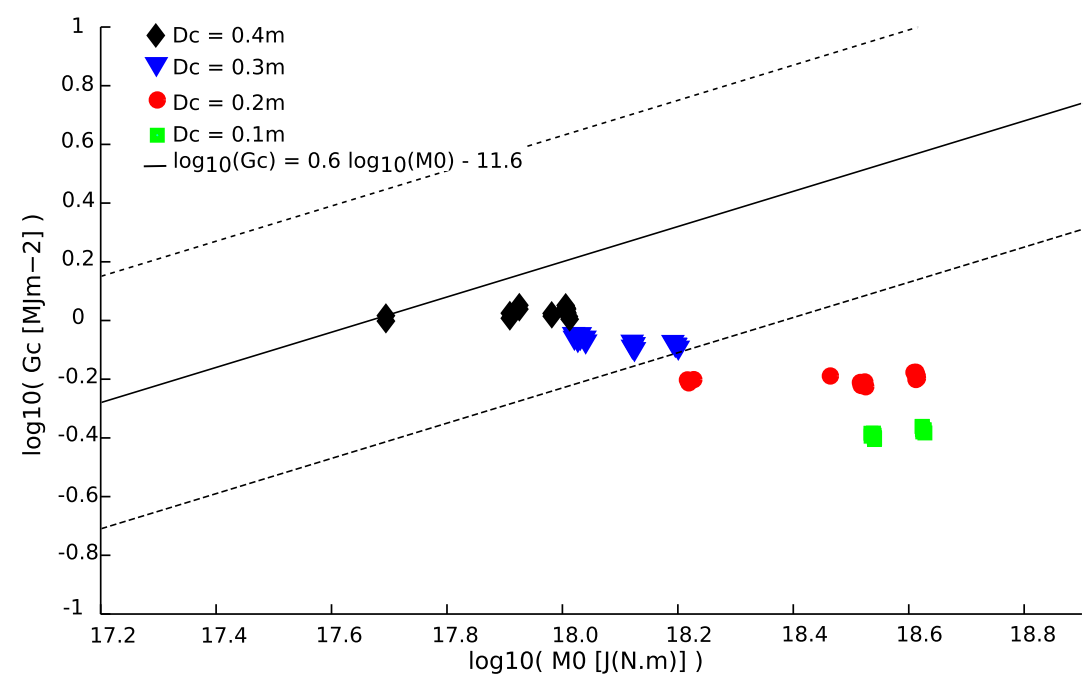

Figure 4. Comparison between the results of our simulations (filled symbols) with the scaling law determined by Causse et al. (2014) (black line), in order to estimate the weight of each $D_{c}$ hypothesis.

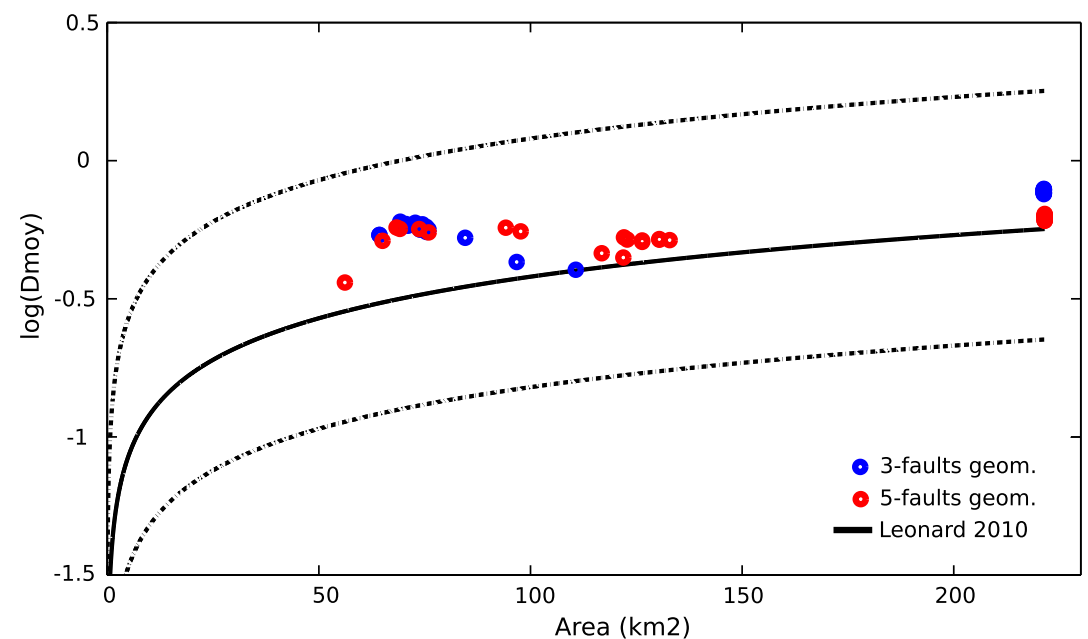

Figure 5. Average displacement versus rupture length. The coloured circles are the values obtained with the numerical simulations. The black line is the scaling law from Leonard (2010), with its uncertainties. Our results are in good agreement with the prediction of Leonard (2010).

central fault, the Neos-Erineos, which is less favourably oriented relative to the regional stress field. Consequently, if the rupture propagates on this fault, it will automatically propagate on the two others. To verify this assumption, we simulate dynamic ruptures that nucleate on the Neos-Erineos fault for different values of $D_{c}$. These simulations show that indeed, once the Neos-Erineos fault has ruptured, the rupture systematically propagates on the Aigion and Psathopyrgos faults, even for $D_{c}$ larger than $0.2 \mathrm{~m}$. This reveals that the propagation of the rupture is controlled by the orientation of the central fault.

For the three-fault geometry, the minimum magnitude, 5.9, is obtained for $D_{c}=0.4 \mathrm{~m}$, with a rupture initiating on the Psathopyrgos fault at the beginning of its cycle and breaking only that single segment. The maximum magnitude, 6.4 , is obtained for $D_{c} \leq 0.2 \mathrm{~m}$ (Table 2), with a rupture breaking the whole fault system ( 50 per cent of occurrence).

\subsubsection{The five-fault geometry}

The simulations with the five fault geometry show more complexity in the rupture propagation (Fig. 7 and Table 2). With this fault configuration, the majority of the ruptures propagate on all five faults ( 40 per cent). Only 25 per cent of the ruptures propagate only on the nucleation fault, and 31 per cent propagate on two faults. In a few cases ( 4 per cent), the rupture propagates on three faults. For $D_{c}$ different from $0.2 \mathrm{~m}$, the rupture propagation is independent from the hypocentre location and from the position of the faults in the seismic cycle (Table 2). For $D_{c}=0.2 \mathrm{~m}$, we observe more variability in the rupture propagation, dependent on the parameter $\mathrm{c}$ and on the nucleation fault.

When we nucleate on the Psathopyrgos fault, rupture propagates either on two or five faults, as a function of the position in the seismic cycle of the Aigion, Fassouleika, Seliantika and Lambiri faults. For a nucleation on the Aigion fault, we observe even more complexity: the rupture propagates on three or five faults, depending on the c parameter (Table 2). If the value of $c_{1}$ on Aigion, Fassouleika, Selianitika and Lambiri faults is equal to 0.4 , the rupture propagates through all the faults. For $c_{1}=0.3$ and $c_{2}=0.5$, the rupture propagates only on three faults. For $c_{1}=0.3$ and $c_{2}=0.9$, the rupture also propagates on all the faults, but jumps from the Selianitika fault to the Psathopyrgos fault, to afterwards come back on Lambiri fault (Fig. 8). This can be explained by the fact that the Lambiri 
(a) $\mathrm{Dc}=0.4 \mathrm{~m} \mathrm{C}_{1}=0.3 \mathrm{C}_{2}=0.5$
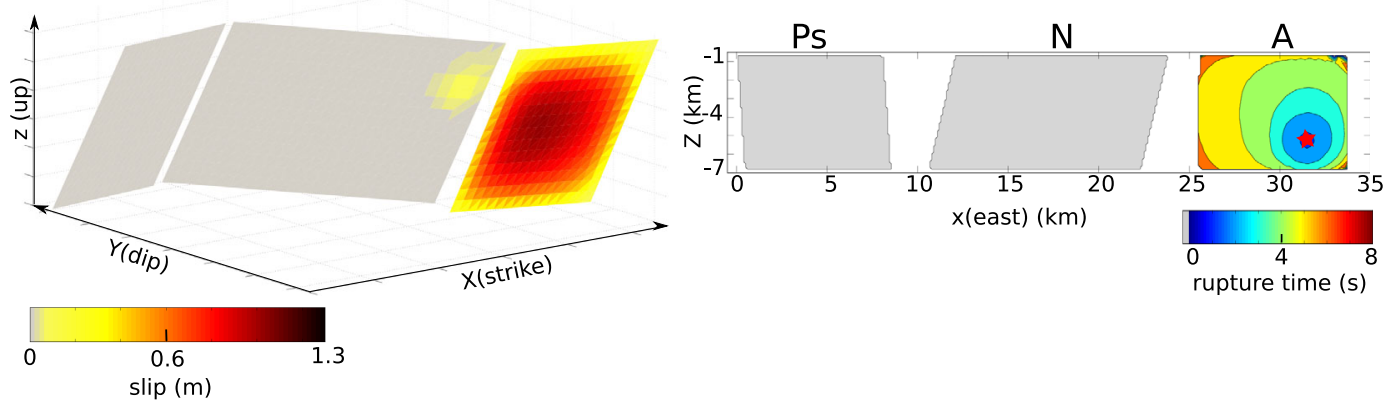

(b) $\mathrm{Dc}=0.1 \mathrm{~m} \mathrm{C}_{1}=0.3 \mathrm{C}_{2}=0.5$
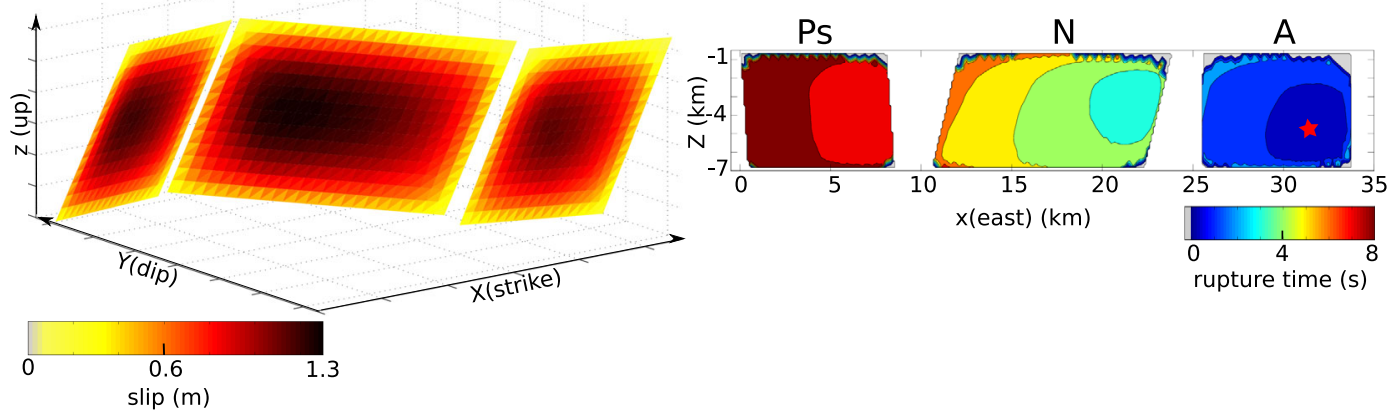

Figure 6. Examples of the dynamic rupture simulations in the case of the three-fault geometry. In these examples, the rupture initiates on the Aigion fault (red star). Slip distribution and rupture time are shown. The only difference between (a) and (b) is the value of the Dc parameter. Contours are every second. P: Psatopyrgos fault; N: Neos-Erineos fault; A: Aigion fault.

Table 2. Summary of the results of the simulations. For the five-faults geometry, the dash means that the result is independent of the seismic cycle combination.

\begin{tabular}{|c|c|c|c|c|c|c|c|}
\hline & \multicolumn{6}{|c|}{ Geometry: 3-fault segments } & \\
\hline & $\begin{array}{l}\text { Critical slip } \\
\text { displacement }\end{array}$ & $\begin{array}{l}\text { Number of } \\
\text { ruptured segments }\end{array}$ & $\begin{array}{l}\text { Segment } \\
\text { name }\end{array}$ & $\begin{array}{l}\text { Appearance } \\
\text { frequency }\end{array}$ & $\begin{array}{l}\text { Magnitude } \\
\text { range }\end{array}$ & $\begin{array}{l}\text { Probability } \\
\text { range }\end{array}$ & \\
\hline & \multirow[t]{2}{*}{$0.4 \mathrm{~m}$} & 1 & A & 4 & {$[6.0-6.1]$} & {$[0.30 \%$ to $0.37 \%]$} & \\
\hline & & & $\mathrm{P}$ & 4 & {$[5.95-6.0]$} & {$[0.71 \%$ to $0.87 \%]$} & \\
\hline & \multirow[t]{2}{*}{$0.3 \mathrm{~m}$} & 1 & A & 4 & [6.02-6.03] & {$[0.24 \%$ to $0.30 \%]$} & \\
\hline & & & $\mathrm{P}$ & 4 & {$[6.01-6.02]$} & {$[0.57 \%$ to $0.7 \%]$} & \\
\hline & \multirow{2}{*}{$\begin{array}{l}0.2 \mathrm{~m} \\
0.1 \mathrm{~m}\end{array}$} & 3 & All & 8 & 6.41 & {$[0.10 \%$ to $0.27 \%]$} & \\
\hline & & 3 & All & 8 & 6.42 & {$[0.08 \%$ to $0.12 \%]$} & \\
\hline \multicolumn{8}{|c|}{ Geometry: 5-fault segments } \\
\hline $\begin{array}{l}\text { Critical slip } \\
\text { displacement }\end{array}$ & $\begin{array}{l}\text { Number of } \\
\text { ruptured segments }\end{array}$ & $\begin{array}{l}\text { Segment } \\
\text { name }\end{array}$ & $\begin{array}{l}\text { Hypocentre } \\
\text { location }\end{array}$ & $\begin{array}{l}\text { Seismic } \\
\text { cycle }\end{array}$ & $\begin{array}{l}\text { Appearance } \\
\text { frequency }\end{array}$ & $\begin{array}{l}\text { Magnitude } \\
\text { range }\end{array}$ & $\begin{array}{l}\text { Probability } \\
\text { range }\end{array}$ \\
\hline \multirow[t]{2}{*}{$0.4 \mathrm{~m}$} & 1 & A & A & - & 4 & [5.80-5.94] & [2.7\% to $3.3 \%$ ] \\
\hline & & $\mathrm{P}$ & $\mathrm{P}$ & - & 4 & [5.99-6.01] & {$[6.3 \%$ to $7.8 \%]$} \\
\hline \multirow[t]{2}{*}{$0.3 \mathrm{~m}$} & 2 & $\mathrm{~A}, \mathrm{~F}$ & A & - & 4 & 6.08 & {$[2.2 \%$ to $2.7 \%]$} \\
\hline & & $\mathrm{P}, \mathrm{L}$ & $\mathrm{P}$ & - & 4 & 6.13 & {$[5.1 \%$ to $6.3 \%]$} \\
\hline \multirow[t]{8}{*}{$0.2 \mathrm{~m}$} & 2 & $\mathrm{P}, \mathrm{L}$ & $\mathrm{P}$ & $c_{1}=0.3 c_{2}=0.9$ & 1 & 6.15 & $2.4 \%$ \\
\hline & & & & $c_{1}=0.3 c_{2}=0.5$ & 1 & 6.14 & $2.2 \%$ \\
\hline & 3 & A,F,S & A & $c_{1}=0.3 c_{2}=0.5$ & 1 & 6.15 & $0.9 \%$ \\
\hline & 5 & A,F,S,L,P & A & $c_{1}=0.4 c_{2}=0.9$ & 1 & 6.35 & $1.0 \%$ \\
\hline & & & & $c_{1}=0.4 c_{2}=0.5$ & 1 & 6.35 & $0.9 \%$ \\
\hline & & A,F,S,P,L & A & $c_{1}=0.3 c_{2}=0.9$ & 1 & 6.35 & $1.0 \%$ \\
\hline & & $\mathrm{P}, \mathrm{L}, \mathrm{S}, \mathrm{F}, \mathrm{A}$ & $\mathrm{P}$ & $c_{1}=0.4 c_{2}=0.9$ & 1 & 6.35 & $2.2 \%$ \\
\hline & & & & $c_{1}=0.4 c_{2}=0.5$ & 1 & 6.34 & $2.0 \%$ \\
\hline \multirow[t]{2}{*}{$0.1 \mathrm{~m}$} & 5 & A,F,S,L,P & A & - & 4 & {$[6.35-6.36]$} & {$[0.3 \%$ to $0.4 \%]$} \\
\hline & & $\mathrm{P}, \mathrm{L}, \mathrm{S}, \mathrm{F}, \mathrm{A}$ & $\mathrm{P}$ & - & 4 & 6.36 & {$[0.7 \%$ to $0.9 \%]$} \\
\hline
\end{tabular}


(a) $\mathrm{Dc}=0.2 \mathrm{~m} \mathrm{C}_{1}=0.3 \mathrm{C}_{2}=0.5$
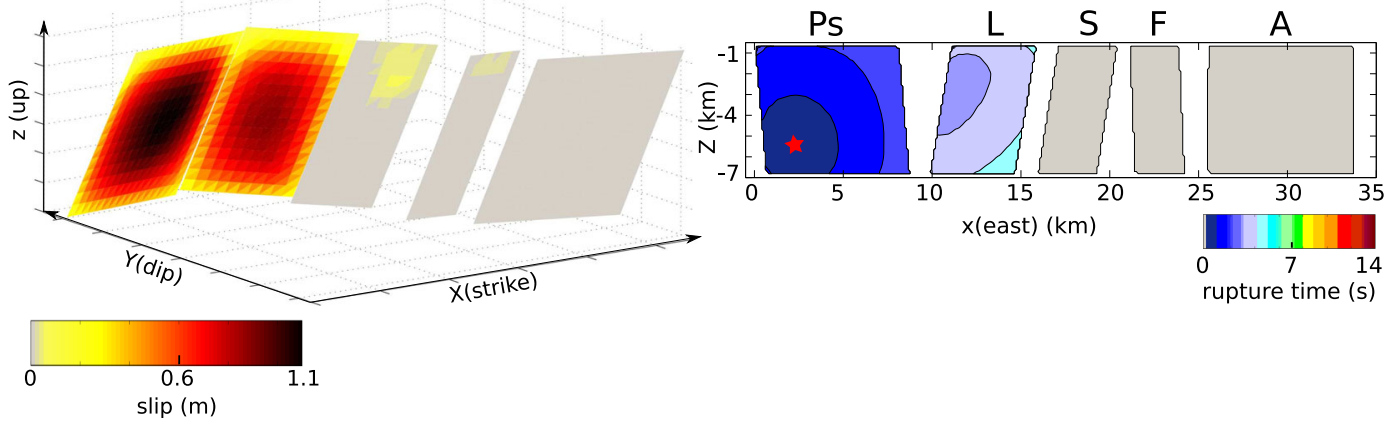

(b) $\mathrm{Dc}=0.2 \mathrm{~m} \mathrm{C}_{1}=0.3 \mathrm{C}_{2}=0.9$
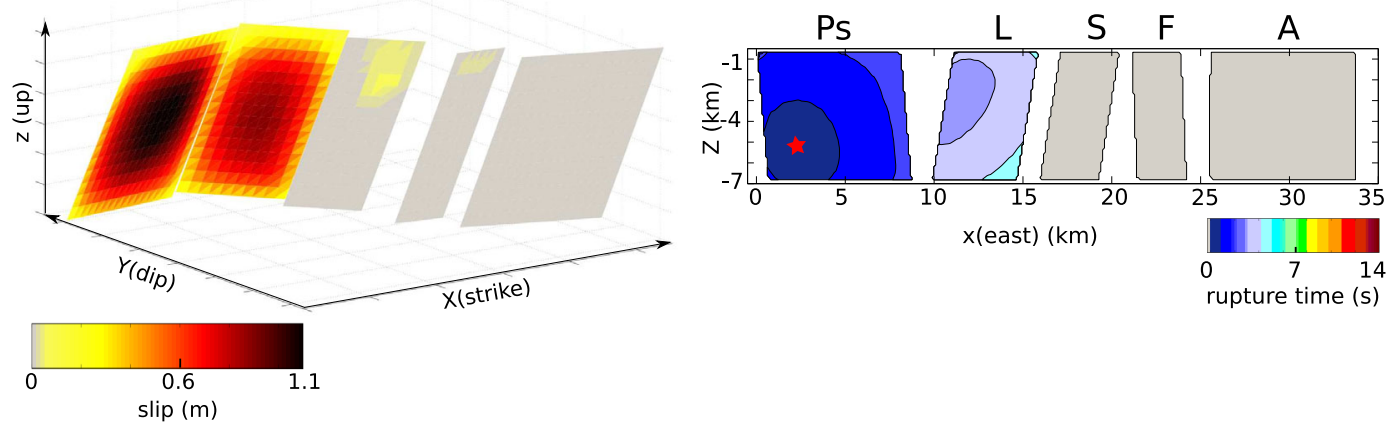

(c) $\mathrm{Dc}=0.2 \mathrm{~m} \mathrm{C}_{1}=0.3 \mathrm{C}_{2}=0.5$
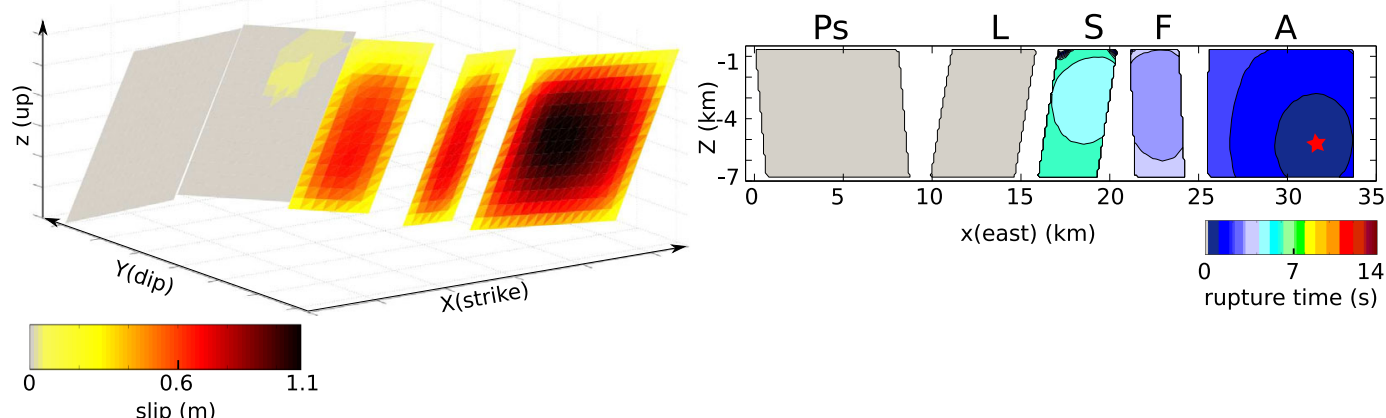

(d) $\mathrm{Dc}=0.2 \mathrm{~m} \mathrm{C}_{1}=0.4 \mathrm{C}_{2}=0.9$
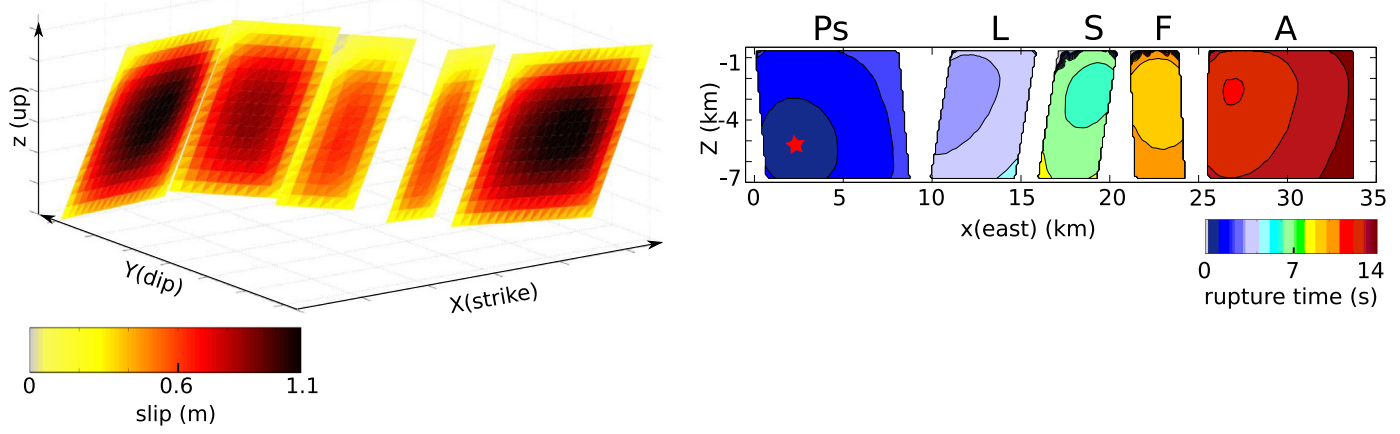

Figure 7. Examples of dynamic rupture simulations in the case of the five-fault geometry. The varying parameters in these examples are the positions of the faults in their seismic cycle [ $c_{1}$ for Aigion (A), Fassouleika (F), Selianitika (S) and Lambiri (L) faults, and $c_{2}$ for the Psathopyrgos (Ps) fault]. Contours are every second. The red stars show the nucleation location for each case. 

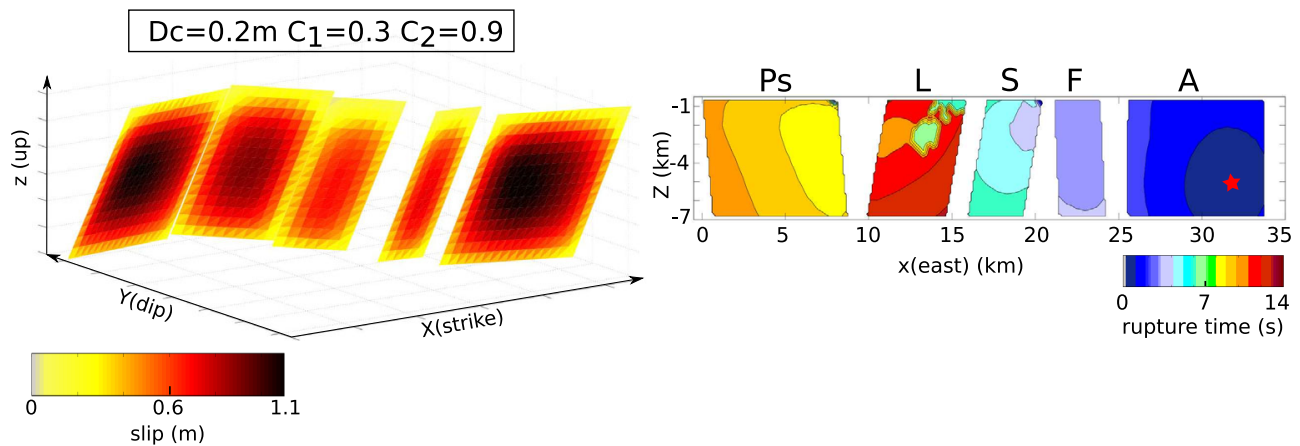

Figure 8. Example of a particular case. The difference with the Fig. 7(b) is that here the rupture nucleates on the Aigion fault (red star). We observe on the rupture time that the rupture jumps over the Lambiri fault from the Selianitika fault to the Psathopyrgos one, and then propagates backward on the Lambiri fault. Contours are every second.

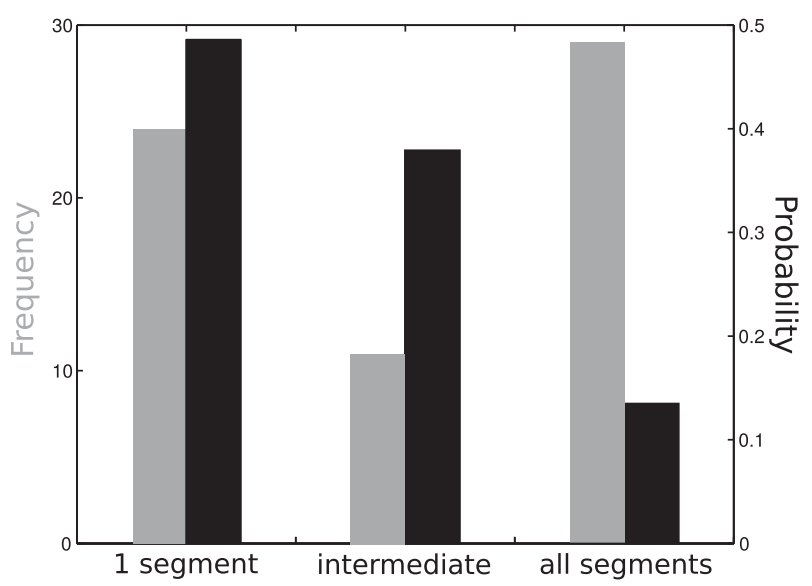

Figure 9. Observed frequency (left bars) and estimated probability (right bars) of the rupture scenarios. The 'intermediate' label means that more than one but less than all the faults broke.

fault is at the beginning of its seismic cycle and unfavourably oriented. Thus, the stress changes induced by the rupture of the three previous segments are not sufficient to make it break, as supported by Fig. 7(c), where the rupture stops on the Selianitika fault. However, the stress changes are big enough to trigger a rupture on the Psathopyrgos fault, which is well oriented relative to the regional stress field and near the end of its seismic cycle $\left(c_{2}=0.9\right)$. Then, the stress changes induced by the rupture of the Aigion, Fassouleika, Seliantika and Psathopyrgos faults are sufficient for the rupture to propagate on the Lambiri fault. We obtain a minimum magnitude of 5.8 for $D_{c}=0.4 \mathrm{~m}$, with nucleation on the Aigion fault. We obtain a maximum magnitude of 6.3 for $D_{c} \leq 0.2 \mathrm{~m}$.

\subsection{Probability estimations}

We distribute the simulations into three groups: single-fault rupture scenario, intermediate scenario with two, three or four broken faults, and an all segments scenario, when all the faults ruptured (resulting in three or five segments depending on geometry). Note that intermediate scenario for the three-fault geometry was never seen. Weighting our scenarios according to the level of confidence of the tested parameters, we then quantify the probabilities for each scenario (Fig. 9 and Table 2) by summing all the probabilities of the corresponding simulations. It highlights that the scenarios that appear more frequently in our simulations (whole network rupture) are the less likely to be observed statistically. It means that the combinations of parameters tested in this study easily produce a total rupture of the network. However, the probability that these combinations really exist is small.

Thus, we see that the single fault scenario is the most likely (48 per cent of probability), with corresponding magnitudes ranging from 5.8 to 6.1 . To the contrary, the whole network is unlikely to break at once ( 14 per cent of probability, see Table 2, the three and five ruptured segments scenarios). However, the intermediate scenarios, implying two or three faults, are very possible (38 per cent of probability). These results also tell us that earthquakes of magnitude between 5.8 and 6.2 are very possible ( 86 per cent of probability). They are compliant with the historical magnitudes (Albini et al. 2016). Even if less likely (14 per cent), earthquakes with magnitude larger than 6.3, involving the whole network, have also to be taken into consideration for seismic hazard assessment.

\section{DISCUSSION}

Before applying these results to seismic hazard assessment, we have to recall that some assumptions we made have a strong influence on the simulations. First, we impose an overshoot of $0.1 \mathrm{MPa}$ inside the nucleation zone. This overshoot is set to be in favour of the rupture initiation, on at least one fault segment. However, stress may actually not have accumulated enough to promote nucleation or propagation of any rupture. The probabilities computed in this study are strongly based on the assumption that the nucleation fault is loaded enough to rupture. Also, for the sake of simplicity, we have assumed quite uniform and spatially homogeneous distributions and values for the dynamic parameters (friction, stress). Introducing variability in the dynamic parameters would change the results of the scenarios. We also consider a homogeneous medium, due to the constraints of the code. However, this is in agreement with the work of Rigo et al. (1996). Furthermore, it has little influence on the lateral rupture propagation if we consider that the triggering occurs at depth. And if we considered a gradient in the medium properties, the wave speed being higher at depth, it would imply that the triggering of the rupture would be deeper than what we observe. We included a free surface in our simulations, but the faults we designed did not reach the surface, for numerical reasons. First, the design of the mesh would have to be finer, resulting in longer computation times. Second, the code has not been validated so far for the free surface rupture. This requires a specific work, including taking into account subsurface medium properties, that we cannot model with this code today. Yet, geological studies show that the faults that form the system we consider reach the surface (Flotté 2003; Boiselet 2014). So future studies should incorporate free surface dynamic breaking. 
Indeed, the impact of the shallow slip on the dynamic propagation of rupture between segments is difficult to anticipate, as well as its consequences on our statistics.

We have to handle carefully the final magnitudes we obtain, because they are strongly dependent on the total surface area of the faults. Stopping the faults at $7 \mathrm{~km}$ depth may imply an underestimation of the magnitude. Comparing our results with maximal magnitudes estimated from the size of the faults (Boiselet 2014), we note that the simulated magnitudes are compatible with the historical ones (Albini et al. 2016), but lie on the lower limit of the recorded palaeoearthquakes. Our model correctly covers the first part of the estimated maximum magnitude interval, which lies between 5.8 and 7.0, depending on which and how many faults break (scaling law from Wells \& Coppersmith 1994; Boiselet 2014), but stops too soon with $M_{\max }=6.4$. This discrepancy may be at least partly explained by the fact that the modelled faults do not reach the surface. The fixed stress drop has also to be considered: we set it to $4 \mathrm{MPa}$. Even if it is already a large value, in future work, we should investigate higher values for this parameter. We should as well consider partial stress drop instead of total stress drop. A last uncertainty comes from the assumed stopping depth of the rupture, at $7 \mathrm{~km}$; it may be possible that some deeper fault segments exist, cutting through, or subparallel to the microseismic layer under the gulf, as suggested by Lambotte et al. (2014), which could be involved in the dynamic rupture together with the shallower segments. There is thus a clear need to investigate the influence of these segments on the maximum magnitude that can be reached, which is an essential point for the seismic hazard evaluation. A simple increase of the width of the faults, or of the stress drop, keeping the other model parameters distribution unchanged, will just shift our magnitude distribution, increasing both the predicted minimal and maximal magnitudes. However, to really make the cascading model and the resulting magnitude distribution more realist and broadened, one should introduce a smaller-scale segmentation of the faults.

\section{CONCLUSIONS}

We performed 3-D dynamic rupture simulations along the AigionPsathopyrgos fault network, south of Corinth Gulf, to evaluate the conditions for a multisegment rupture and estimate the associated magnitudes. With this study, we have highlighted the strong influence of the fracture energy, through the $D_{c}$ parameter, on the rupture propagation and final magnitudes. We have also shown that a rupture that nucleates on the Psathopyrgos or Aigion fault can propagate on several faults, as inferred by the study of palaeoearthquakes (Boiselet 2014). From the computation of scenario probabilities, we bring to light that with acceptable fracture energy values, the scenario implying the simultaneous rupture of all the faults, in an $M=6.4$ over $30 \mathrm{~km}$, is the less likely-but not excluded. However, multisegment rupture scenarios are achievable, with magnitudes up to 6.1 and $15 \mathrm{~km}$ in length, and have to be taken into consideration in the seismic hazard assessment.

\section{ACKNOWLEDGEMENTS}

We thank Hideo Aochi for fruitful discussions and explanations about his 2006 paper at the beginning of this work. We also thank Nicolas Meyer and Mary Ford for sharing their experience and expertise on the geology of the region, providing useful indications on the geometry of the faults. This work benefited from the support of the ANR project SISCOR and the EC project REAKT.

\section{REFERENCES}

Albini, P., Rovida, A., Scotti, O. \& Lyon-Caen, H., 2016. Large 18th-19th centuries earthquakes in Western Gulf of Corinth with reappraised size and location, Bull. seism. Soc. Am., submitted.

Ambraseys, N.N. \& Jackson, J.A., 1997. Seismicity and strain in the Gulf of Corinth (Greece) since 1694, J. Earthq. Eng., 1, 433-474.

Andrews, D.J., 1976. Rupture velocity of plane strain shear crack, J. geophys. Res., 81, 3679-3687.

Andrews, D.J. \& Schwerer, E., 2000. Probability of rupture of multiple fault segments, Bull. seism. Soc. Am., 90, 1498-1506.

Aochi, H. \& Fukuyama, E., 2002. Three-dimensional nonplanar simulation of the 1992 Landers earthquake, J. geophys. Res., 107(B2), ESE 4-1-ESE 4-12.

Aochi, H. \& Ulrich, T.A., 2015. A probable earthquake scenario near Istanbul determined from dynamic simulations, Bull. seism. Soc. Am., 105, 1468-1475.

Aochi, H., Fukuyama, E. \& Matsu'ura, M., 2000. Spontaneous rupture propagation on a non-planar fault in 3-D elastic medium, Pure appl. Geophys., 157, 2003-2027.

Aochi, H., Cushing, M., Scotti, O. \& Berge-Thierry, C., 2006. Estimating rupture scenario likelihood based on dynamic rupture simulations: the example of the segmented Middle Durance fault, southeastern France, Geophys. J. Int., 165, 436-446.

Avallone, A. et al., 2004. Analysis of eleven years of deformation measured by GPS in the Corinth Rift Laboratory area, C. R. Geosci., 336, 301-311.

Bernard, P. et al., 2006. Seismicity, deformation and seismic hazard in the western rift of Corinth: new insights from the Corinth Rift Laboratory (CRL), Tectonophysics, 426, 7-30.

Boiselet, A., 2014. Cycle sismique et aléa sismique d'un réseau de failles actives: le cas du rift de Corinthe (Grèce), PhD thesis, Ecole Normale Supérieure, Paris, France.

Briole, P. et al., 2000. Active deformation of the Corinth rift, Greece: results from repeated Global Positioning System surveys between 1990 and 1995, J. geophys. Res., 105(B11), 25 605-25 625.

Causse, M., Dalguer, L.A. \& Mai, P.M., 2014. Variability of dynamic source parameters inferred from kinematic models of past earthquakes, Geophys. J. Int., 196(3), 1754-1769.

Cocco, M., Tinti, E., Marone, C. \& Piatanesi, A., 2009. Scaling of slip weakening distance with final slip during dynamic earthquake rupture, in Fault-Zone Properties and Earthquake Rupture Dynamics, pp. 163-186, Vol. 94, ed. Fukuyama, E., Elsevier.

Cruz-Atienza, V., Olsen, K.B. \& Dalguer, L.A., 2009. Estimation of the breakdown slip from strong-motion seismograms: insights from numerical experiments, Bull. seism. Soc. Am., 99, 3454-3469.

Douilly, R., Aochi, H., Calais, E. \& Freed, A.M., 2015. 3D dynamic rupture simulations across interacting faults: the Mw 7.0, 2010, Haiti earthquake, J. geophys. Res., 120, 1108-1128.

Drakatos, G., Karantonis, G. \& Stavrakakis, G.N., 1997. P-wave crustal tomography of Greece with use of an accurate two-point ray tracer, Anna. Geofis., 40, 25-36.

Finzi, Y. \& Langer, S., 2012. Damage in step-overs may enable large cascading earthquakes, Geophys. Res. Lett., 39, doi:10.1029/2012GL052436.

Flotté, N., 2003. Caractérisation structurale et cinématique d'un rift sur détachement: le rift de Corinthe-Patras, Grèce, $P h D$ thesis, Université Paris-Sud, France.

Guatteri, M. \& Spudich, P., 2000. What can strong-motion data tell us about slip-weakening faukt-friction laws?, Bull. seism. Soc. Am., 90, 264-282.

Harris, R.A., Archuleta, R.J. \& Day, S.M., 1991. Fault steps and the dynamic rupture process: 2-D numerical simulations of a spontaneously propagating shear fracture, Geophys. Res. Lett., 18, 893-896.

Hatzfeld, D., Karakostas, V., Ziazia, M., Kassaras, I., Papadimitriou, E., Makropoulos, K., Voulgaris, N. \& Papaioannou, C., 2000. Microseismicity and faulting geometry in the Gulf of Corinth (Greece), Geophys. J. Int., 141, 438-456.

Hok, S. \& Fukuyama, E., 2011. A new BIEM for rupture dynamics in halfspace and its application to the 2008 Iwate-Miyagi Nairiku earthquake, Geophys. J. Int., 184, 301-324. 
Hok, S., Fukuyama, E. \& Hashimoto, C., 2011. Dynamic rupture scenarios of anticipated Nankai-Tonankai earthquakes, southwest Japan, J. geophys. Res., 116, B12319, doi:10.1029/2011JB008492.

Ida, Y., 1972. Cohesive force across the tip of a longitudinal-shear crack and Griffith's specific surface energy, J. geophys. Res., 77, 3796-3805.

Ide, S. \& Takeo, M., 1997. Determination of constitutive relations of fault slip based on seismic wave analysis, J. geophys. Res., 102(B12), 27379 27391.

Kase, Y. \& Kuge, K., 1998. Numerical simulation of spontaneous rupture processes on two non-coplanar faults: the effect of geometry on fault interaction, Geophys. J. Int., 135, 911-922.

Lambotte, S. et al., 2014. Reassessment of the rifting process in the Western Corinth Rift from relocated seismicity, Geophys. J. Int., 197, 1822-1844.

Leonard, M., 2010. Earthquake fault scaling: self-consistent relating of rupture length, width, average displacement, and moment release. Bull. seism. Soc. Am., 100, 1971-1988.

Lozos, J.C., Oglesby, D.D., Brune, J.N. \& Olsen, K.B., 2015. Rupture propagation and ground motion of strike-slip stepovers with intermediate fault segments, Bull. seism. Soc. Am., 105, 387-399.

Lyon-Caen, H., Papadimitriou, P., Deschamps, A., Bernard, P., Makropoulos, K., Pacchiani, F. \& Patau, G., 2004. First results of the CRLN seismic network in the western Corinth Rift: evidence for old-fault reactivation, C. R. Geosci., 336, 343-351.

Marone, C. \& Scholz, C., 1988. The depth of seismic faulting and the upper transition from stable to unstable slip regimes, Geophys. Res. Lett., 15, 621-624.

Mikumo, T., Olsen, K.B., Fukuyama, E. \& Yagi, Y., 2003. Stress-breakdown time and critical weakening slip inferred from the source time functions on earthquake faults, Bull. seism. Soc. Am., 93, 264-282.

Oglesby, D.D., 2005. The dynamics of strike-slip step-overs with linking dip-slip faults, Bull. seism. Soc. Am., 95, 1604-1622.

Pacchiani, F. \& Lyon-Caen, H., 2010. Geometry and spatio-temporal evolution of the 2001 Agios Ioanis earthquake swarm (Corinth Rift, Greece), Geophys. J. Int., 180, 59-72.

Palyvos, N., Pantosti, D., De Martini, P.M., Lemeille, F., Sorel, D. \& Pavlopoulos, K., 2005. The Aigion-Neos Erineos coastal normal fault system (western Corinth Gulf Rift, Greece): geomorphological signature, recent earthquake history, and evolution, J. geophys. Res., 110(B9), B09302, doi:10.1029/2004JB003165.
Pantosti, D., Martini, P.M.D., Koukouvelas, I., Stamatopoulos, L., Palyvos, N., Pucci, S., Lemeille, F. \& Pavlides, S., 2004. Paleoseismological investigations of the Aigion fault (Gulf of Corinth, Greece), C. R. Geosci., 336, 335-342.

Papazachos, B.C. \& Papazachou, C., 1997. The Earthquakes of Greece, Ziti Publ. Co., 286 pp.

Pulido, N. \& Dalguer, A.L., 2009. Estimation of the high-frequency radiation of the 2000 Tottori (Japan) earthquake based on a dynamic model of fault rupture: application to the strong ground motion simulation, Bull. seism. Soc. Am., 99, 2305-2322.

Rigo, A., Lyon-Caen, H., Armijo, R., Deschamps, A., Hatzfeld, D., Makropoulos, K., Papadimitriou, P. \& Kassaras, I., 1996. A microseismic study in the western part of the Gulf of Corinth (Greece): implications for large-scale normal faulting mechanisms, Geophys. J. Int., 126, 663-688.

Scholz, S.H., 1988. The brittle-plastic transition and the depth of seismic faulting, Geol. Rundsch., 77, 319-328.

Stefatos, A., Papatheodorou, G., Ferentinos, G., Leeder, M. \& Collier, R., 2002. Seismic reflection imaging of active offshore faults in the gulf of Corinth: their seismotectonic significance, Basin Res., 14, 487-502.

Tada, T., Fukuyama, E. \& Madariaga, R., 2000. Non-hypersingular boundary integral equations for 3-D non-planar crack dynamics, Comput. Mech., 25, 613-626.

Tinti, E., Spudich, P. \& Coco, M., 2005. Earthquake fracture energy inferred from kinematic rupture models on extended faults, J. geophys. Res., 110, B12303, doi:10.1029/2005JB003644.

Urata, Y., Kuge, K. \& Kase, Y., 2012. Spontaneous dynamic rupture propagation beyond fault discontinuities: effect of thermal pressurization, Bull. seism. Soc. Am., 102, 53-63.

Wells, D. \& Coppersmith, K.J., 1994. New empirical relationships among magnitude, rupture length, rupture width, rupture area, and surface displacement, Bull. seism. Soc. Am., 84, 974-1002.

Wesnousky, S.G., 2008. Displacement and geometrical characteristics of earthquakes surface ruptures: issues and implications for seismic-hazard analysis and the process of earthquake rupture, Bull. seism. Soc. Am., 98, $1609-1632$.

Westaway, R., 2002. The Quaternary evolution of the Gulf of Corinth, central Greece: coupling between surface processes and flow in lower continental crust., Tectonophysics, 348, 269-318. 